\title{
Conhecimento Profissional de Professores dos Anos Iniciais do Ensino Fundamental Sobre Espaço Amostral e Quantificação de Probabilidades
}

\section{Professional Knowledge of Initial Series Teachers from the Elementary School Regarding Sample Space and Probabilities Quantification}

\author{
Maria Gracilene de Carvalho Pinheiro; ; Angélica da Fontoura Garcia Silva ${ }^{a}$; Ruy César Pietropaolo*a
}

aUniversidade Anhanguera de São Paulo. SP, Brasil.

*E-mail: rpietropaolo@gmail.com

\begin{abstract}
Resumo
Neste texto, discutiu-se parte de uma investigação de Doutorado que teve o objetivo de analisar o desenvolvimento profissional de professores que lecionam Matemática para os Anos Iniciais do Ensino Fundamental em seu trabalho com Probabilidade. Para este artigo, focou-se nos conhecimentos dos participantes referentes à compreensão de espaço amostral e quantificação de probabilidades, manifestados em uma tarefa proposta durante uma formação. Adotando uma metodologia qualitativa, procurou-se descrever e interpretar as resoluções, registradas nos protocolos dos professores, e suas discussões, coletadas em vídeos e áudios gravados. Analisou-se os resultados à luz de teorias e investigações a respeito do ensino e da aprendizagem de Probabilidade e do conhecimento matemático para o ensino da temática. As resoluções, as discussões e as reflexões acerca das noções probabilísticas implicadas na situação analisada desenvolveram e ampliaram os Conhecimentos Comum de Conteúdo e também os Conhecimentos Especializados dos professores, o que, certamente, permitir-lhes-á, no ensino, antecipar erros de seus alunos, identificar possíveis causas, justificá-las do ponto de vista da Matemática e, consequentemente, buscar estratégias de intervenção que favoreçam sua compreensão e sua aprendizagem. Ressaltou-se, nesse processo de desenvolvimento e/ou ampliação dos conhecimentos, a importância de cursos de formação que conduzam à reflexão de questões ligadas tanto ao ensino como à aprendizagem, neste caso, de conceitos matemáticos e, mais especificamente, de noções probabilísticas com crianças em fase inicial de escolarização.
\end{abstract}

Palavras-chave: Formação Contínua. Conhecimento Profissional Docente. Anos Iniciais do Ensino Fundamental. Ensino de Probabilidade.

\begin{abstract}
In this text, it is discusses part of a Doctoral investigation which aimed analyzing the teachers professional development that teach Mathematics for Elementary School Initial Series, on its work with Probability. For this article, we focused on the participants' knowledges regarding the comprehension of sample space and probabilities quantification, expressed in a purposed during a formation. Adopting a qualitative methodology, it was aimed to describe and interpret the resolutions, registered in the teachers protocols and their discussions collected in recorded videos audio. The results were analyzed based on theories and investigations regarding the Probability teaching and learning and the mathematical knowledge for the thematic teaching. The resolutions, the long discussions and lots of reflection about the probabilistic notions implied in the analyzed situation, have developed and amplified the teachers' Content Common Knowledge as well as the Specialized Knowledges, what certainly will enable them to anticipate mistakes from their students, identify possible causes, justify them from the Mathematics point of view and, consequently, look for interventional strategies that promote the comprehension and learning. Iin this process, the knowledge development and/or amplification, the importance of formative courses that take the reflection of issues related to both teaching and learning, in this case, the mathematical concepts and, more specifically, the probabilistic notions whith children in schooling initial phase.
\end{abstract}

Keywords: Continuous Formation. Teacher Professional Knowledge. Elementary School Initial Series. Probability Teaching.

\section{Introdução}

O ensino de Probabilidade e Estatística se constitui um contributo fundamental para o desenvolvimento da capacidade de interpretação, análise e argumentação e para a formação cidadã do aluno, tornando-o capaz de posicionar-se criticamente diante de situações que exigem tomada de decisão (Batanero, Gómez, Contreras \& Diaz, 2015; Batanero, 2016; Lopes, 2012; Nacarato \& Grando, 2013; Santos, 2015; Batista \& Borba, 2016). Currículos de vários países - entre eles, o da Espanha, de Portugal, dos Estados Unidos e do Brasil — orientam que noções relativas à Probabilidade devem ser ensinadas desde o início da escolaridade básica até os anos finais e Ensino Médio, além de recomendar que elas sejam incluídas no Ensino Superior. ${ }^{1}$

Diante dessa compreensão, faz-se imprescindível que sejam propiciadas aos estudantes, desde os primeiros anos do Ensino Fundamental, condições para que desenvolvam conhecimentos ligados à Probabilidade e à Estatística. Mas que ideias, noções e conceitos devem ser ensinados e aprendidos nessa fase de escolarização? Que conhecimentos devem ser mobilizados pelos professores na exploração dessa temática em sala de aula? Embora esses questionamentos não tenham se constituído questões de investigação, eles permearam toda esta pesquisa e o processo formativo em que ela foi desenvolvida.

Para discutir o ensino e a aprendizagem de noções 
probabilísticas para crianças em fase inicial de escolarização, realizamos uma formação com professores que ensinam Matemática para alunos dos anos iniciais do Ensino Fundamental na rede estadual de São Paulo. No planejamento e no desenvolvimento de todo o processo formativo, buscamos no Programa Compreensão das Crianças sobre Probabilidade e Risco (Nunes, Bryant, Evans \& Barros, 2011) fundamentos para orientar as discussões sobre questões didáticas referentes ao ensino de Probabilidade e sobre a compreensão de crianças em fase inicial de escolarização sobre os conceitos envolvidos na temática. A escolha de fazer uma formação com essa característica se justifica em estudos como os de Ball, Thames \& Phelps (2008), que argumentam acerca da necessidade de o professor desenvolver conhecimentos relativos ao conteúdo, ao ensino e ao estudante.

O estudo do qual o referido processo formativo configurou parte teve o objetivo de analisar o desenvolvimento profissional dos docentes participantes. Assim, identificouse, entre outros aspectos, os conhecimentos acerca do entendimento de aleatoriedade, descrição e análise de espaço amostral e quantificação de probabilidades. Neste texto, temos a finalidade de apresentar alguns resultados a respeito dos conhecimentos desses professores no que se refere à compreensão de espaço amostral e quantificação de probabilidade, manifestada numa tarefa proposta em uma das sessões de formação.

Para tanto, a seguir, apresentaremos as perspectivas teóricas que fundamentaram a presente investigação. $\mathrm{Na}$ sequência, exporemos os procedimentos metodológicos para o estudo e a recolha dos dados. Logo, analisaremos e discutiremos os resultados. Por último, faremos algumas considerações a respeito deste estudo.

\section{Perspectivas Teóricas e Revisão de Literatura}

Nesta seção, abordaremos os fundamentos teóricos desta pesquisa. Iniciaremos discorrendo sobre a ideia de Conhecimento Profissional. Em seguida, descreveremos o Programa em que este estudo se baseou para fazer a formação. Por fim, trataremos do conhecimento docente sobre Probabilidade e Estatística.

\subsection{Conhecimento Profissional}

Consideramos - com base nas teorias que fundamentam nossas investigações, Conhecimento e Desenvolvimento Profissional Docente, Reflexão e Saberes Docentes - ser indispensável refletir sobre o conhecimento matemático para o desenvolvimento da ação pedagógica do professor. Para tanto, valer-nos-emos dos estudos de Shulman (1996) e Ball et al. (2008).

Em muitos países, desde os anos 1990, percebe-se uma forte preocupação de pesquisadores com o trabalho do professor: valoriza-se o estudo, a análise e a discussão de aspectos ligados à Matemática, compreensão do conceito, e ao ensino, aspectos pedagógicos (Shulman, 1986). No trabalho aqui apresentado, interessou-nos — com vistas a fundamentar a discussão a respeito do conhecimento matemático para a ação pedagógica do professor — analisar os elementos do conhecimento matemático para o ensino de Probabilidade, na perspectiva de Ball et al. (2008). Esses pesquisadores observaram a prática docente, analisaram-na e identificaram conhecimentos para o ensino de Matemática, destacando o conhecimento do conteúdo, que se refere a um tipo de conhecimento matemático diferente daquele exigido a outros profissionais, pois é o "conhecimento matemático necessário para realizar o trabalho de ensinar Matemática" (Ballet al., 2008, p. 395) aos alunos. Trata-se de um conhecimento que, mesmo sujeito a inúmeras influências, possui uma especificidade própria em função de sua atividade e das condições em que tal atividade é exercida (Ponte, 2012).

Ball et al. (2008), apoiados em Shulman (1986), desenvolveram uma teoria segundo a qual domínios de conhecimentos sobre a Matemática devem ser considerados por professores e pesquisadores na docência. São eles: o Conhecimento Matemático do Conteúdo, que contempla o Conhecimento Comum, o Conhecimento do Horizonte do Conteúdo e o Conhecimento Especializado do Conteúdo; e o Conhecimento Pedagógico do Conteúdo, que envolve o Conhecimento do Conteúdo e dos Estudantes, o Conhecimento do Conteúdo e do Ensino e, ainda, o Conhecimento do Conteúdo e do Currículo.

Para este artigo, observaremos aspectos do Conhecimento Comum do Conteúdo (CCK). Ele possui estreita relação com o conteúdo do currículo, porém não é exclusivo ao ensino, também é utilizado em outras situações. Engloba o conhecimento dos conteúdos matemáticos que todos os profissionais que estudaram Matemática deveriam saber, independentemente de serem professores (Ball et al., 2008). Compreende os conhecimentos que levam o professor a, por exemplo, perceber erros conceituais em livros didáticos, utilizar algoritmos, desenvolver procedimentos matemáticos e identificar quando os alunos não o fazem de maneira correta. Trata-se de um conhecimento essencial, mas insuficiente ao ato de ensinar (Ball et al., 2008), pois envolve somente "o conhecimento que os professores precisam para serem capazes de fazer o trabalho que eles atribuem aos seus alunos."

No que se refere ao ensino de Probabilidade para os anos iniciais do Ensino Fundamental, o professor necessitaria, por exemplo, dominar a noção de aleatoriedade, analisar diferentes espaços amostrais. Além disso, precisaria desenvolver a capacidade de selecionar ou elaborar tarefas que levem os alunos a desenvolverem as habilidades de classificar eventos como "possível", "impossível", "provável" ou "improvável", diferenciar eventos aleatórios de eventos não aleatórios e descrever o espaço amostral, especialmente, de eventos simples, mobilizando nas crianças ideias intuitivas fundamentais ao desenvolvimento do pensamento 
probabilístico. Conforme orienta a Base Nacional Curricular Comum (BNCC), essas são habilidades que devem ser desenvolvidas pelos estudantes desde os anos iniciais do Ensino Fundamental (Ministério da Educação, 2017).

\subsection{O Programa Compreensão das Crianças sobre Probabilidade e Risco}

O ensino de Probabilidade pode gerar dificuldades, visto que apresenta características, muitas vezes, contrárias a nossa intuição. A aleatoriedade, por exemplo, gera incertezas que podem ser de difícil compreensão, como vemos neste caso: não sabemos, em um conjunto de eventos possíveis que conhecemos, quais deles vão acontecer, não havendo a possibilidade de determinar quando um evento particular acontecerá nem de prever com certeza a forma como os eventos ocorrem em uma sequência (Nunes et al., 2011).

O Programa Compreensão das Crianças sobre Probabilidade e Risco, desenvolvido por Nunes et al. (2011), discute a possibilidade de um ensino que leve a criança a desenvolver compreensões sobre quatro demandas cognitivas, cuja abordagem se relaciona às ideias que formam o conceito de Probabilidade. Listamo-las a seguir: (1) aleatoriedade; (2) ideias envolvidas no conceito de espaço amostral; (3) estratégias para realizar a comparação e a quantificação de probabilidades; e (4) correlação, relação entre eventos.

O espaço amostral (conjunto de eventos possíveis) desempenha um papel importante, que, muitas vezes, é subestimado nos processos de ensino e aprendizagem de Probabilidade. Por isso, Nunes et al. (2011) orientam que é preciso desenvolver a capacidade de trabalhar com o espaço amostral para compreender e calcular as probabilidades de eventos específicos. Assim, determinar o espaço amostral de um experimento constitui-se como essencial para a resolução de qualquer problema de probabilidade "e em muitos é o mais importante, já que a solução é bastante óbvia para alguém que conheça todas as possibilidades.” (Bryant \& Nunes, 2012, p. 5). A determinação e a análise do espaço amostral dependem tanto do raciocínio contrafactual - situações ou eventos que não aconteceram, mas que poderiam ter acontecido - como do raciocínio combinatório (Nunes et al., 2011).

Aquantificação de probabilidades, em problemas indicados para os anos iniciais, refere-se ao cálculo da probabilidade de um evento específico — cálculos proporcionais (expressos por um número decimal ou uma porcentagem), visto que cada probabilidade é, em si, uma razão entre um resultado específico e o conjunto de resultados possíveis (Nunes et al., 2011). Relaciona-se também à comparação da força de duas ou mais probabilidades.A "probabilidade pode sera mesma em amostras de diferentes tamanhos, porque as probabilidades baseiamse inteiramente em proporções." (Nunes et al., 2011, p. 5).

O risco é visto como mais um aspecto do pensamento probabilístico e depende do raciocínio correlacional (Nunes \& Bryant, 2011). Apoiados em Ross e Primos (1993), Nunes et al. (2011) argumentam que a correlação é uma forma de raciocínio envolvido na determinação da natureza e da força de uma relação mútua entre duas variáveis. "Esse raciocínio exige o reconhecimento que as relações entre variáveis não são absolutas, mas existem em graus e, assim, envolvem raciocínio probabilístico.” (Nunes et al., 2011, p. 6).

Como eles, outros pesquisadores, como Batanero e Godino (2002) e Coutinho (2001), discutem a importância da compreensão de três noções básicas para a construção dos conceitos probabilísticos. São elas: a percepção do acaso, a ideia de experiência aleatória e a concepção de probabilidade.

\subsection{Os conhecimentos do professor e o ensino de Probabilidade e Estatística}

Reiteramos que os conhecimentos sobre a Estatística e a Probabilidade são contributos para a formação cidadã do educando, tornando-o capaz de: analisar situações; posicionarse criticamente; tomar decisões; e resolver problemas do dia a dia em diferentes áreas (Batanero, 2016; Lopes, 2003). Além disso, a compreensão de noções probabilísticas e estatísticas constitui etapa necessária ao desenvolvimento do pensamento matemático (Batanero e Godino, 2002; Campos \& Pietropaolo, 2013; Cardeñoso \& Azcárate, 1995; Gal, 2005), favorecendo a retomada e/ou a ampliação de noções relativas aos números racionais e às medidas de grandezas, como comprimento e área. O trabalho com essas áreas do saber proporciona um contexto favorável à construção de significados dos diferentes tipos de agrupamentos, contribuindo para o desenvolvimento do pensamento combinatório e do pensamento estatístico (Campos \& Pietropaolo, 2013).

Investigações acerca dessa temática apontam que nos primeiros anos de estudo é possível mobilizar nas crianças ideias intuitivas fundamentais ao desenvolvimento do pensamento probabilístico e de outras noções matemáticas, como a de proporcionalidade (Batanero et al., 2015; Batista \& Borba, 2016; Fernandes, Serrano \& Correia, 2016; Santos, 2015). Porém, estudos referentes ao conhecimento profissional e às práticas de professores atuantes apontam que algumas dificuldades pedagógicas são enfrentadas no ensino pelos professores, em especial por aqueles dos anos iniciais (Batanero, Godino \& Roa, 2004), exigindo deles a procura por informações e tarefas para serem desenvolvidas em sala de aula (Dias, 2004). Em sua formação inicial, os docentes aprendem aspectos da Estatística e da Probabilidade; no entanto, eles são, por vezes, insuficientes para o exercício da docência, pois, além dos conhecimentos dos conteúdos, são necessários os didáticos específicos (Cazorla, 2009).

Diante dessa compreensão, há um forte apelo para investimentos nos cursos de formação inicial e continuada. A abordagem destes deve estar voltada para questões relacionadas aos processos de ensino e de aprendizagem, como: o estudo do raciocínio das crianças e as diferentes estratégias que podem ser adotadas pelo professor na exploração do conceito de Probabilidade (Batanero et al., 2015; Campos \& Carvalho, 2016); e, ainda, a produção de materiais didáticos 
que subsidiem o trabalho docente (Fernandes et al., 2016, Kataoka, Rodrigues \& Oliveira, 2007, Silva, 2011).

\section{Procedimentos Metodológicos}

O presente estudo segue uma metodologia de investigação de natureza qualitativa (Bogdan \& Biklen, 1999) e foi desenvolvido com o objetivo de analisar os conhecimentos dos participantes sobre o espaço amostral e a quantificação de probabilidades manifestados em uma tarefa proposta durante uma formação. O contexto desta investigação foi uma formação realizada no âmbito do Projeto Observatório da Educação ${ }^{2}$, um projeto de formação e pesquisa constituído por professores e pesquisadores da área da Educação Matemática, ligado ao Programa de Pós-Graduação em Educação Matemática da Universidade Anhanguera de São Paulo (UNIAN-SP), localizada no Brasil, e financiado pela Coordenação de Aperfeiçoamento de Pessoal de Nível Superior (Capes), órgão oficial do governo federal. O referido projeto - OBEDUC/2013 - almeja a constituição de grupos colaborativos de formação e pesquisa, a fim de investigar a prática docente e contribuir para transformá-la e promover o desenvolvimento profissional de professores que lecionam Matemática, quando inseridos em um processo de pesquisa em Educação Matemática e motivados a promover inovações curriculares em suas aulas.

O processo formativo, cuja carga horária foi de 32 horas, ocorreu na sede da Diretoria de Ensino Norte 2 rede estadual de ensino de São Paulo — em 8 sessões de 4 horas, no período de 6 meses. Os autores desta produção foram os pesquisadores responsáveis pela formação, cujo objetivo central foi explorar, por meio de atividades variadas, conceitos básicos relativos ao ensino de Probabilidade nos anos iniciais do Ensino Fundamental. No planejamento e no desenvolvimento da formação, buscamos referências no Programa Compreensão das Crianças sobre Probabilidade e Risco (Nunes et al., 2011).

Conforme já mencionado, a análise dos dados focará em questões ligadas ao Conhecimento Comum do Conteúdo (Ball et al., 2008) dos professores participantes sobre as informações coletadas em uma tarefa desenvolvida em uma das sessões de formação. Para tanto, os dados recolhidos em vídeos e áudios produzidos durante as sessões de formação foram transcritos e explorados e interpretados com base nas categorias de conhecimentos estabelecidas por Ball et al. (2008).

\subsection{O estudo e a recolha dos dados}

O estudo aqui descrito faz um recorte de uma pesquisa de Doutorado em Educação Matemática desenvolvida pela primeira autora. Participaram dessa investigação professores que lecionam Matemática para os anos iniciais do Ensino
Fundamental da rede estadual de São Paulo. Os dados analisados neste artigo são referentes aos conhecimentos adquiridos, desenvolvidos ou ampliados pelos professores acerca da Probabilidade, evidenciados nas resoluções da tarefa proposta em uma das sessões de formação (Quadro 1).

Quadro 1 - Tarefa para explorar conceitos probabilísticos

Nome: $\quad$ Tarefa Saco de Doces

Samantha pode pegar, de um saco que contém três doces, sem olhar, dois doces. Nele, há dois doces de morango e um doce de baunilha. Seu sabor favorito é morango. Ao pegar os doces, ela pode ficar com dois doces de morango ou com um de morango e um de baunilha.

* Em sua opinião, Samantha possui melhor chance de conseguir dois doces de morango ou de obter uma mistura (um de morango e um de baunilha)? Ou você acha que a chance de ela escolher dois doces de morango ou uma mistura é a mesma?

* Anote aqui suas reflexões sobre suas suposições:

O que levou você a pensar que Samantha tem uma maior chance de escolher dois doces de morango? O que levou você a pensar que ela tem uma maior chance de escolher uma mistura? O que leva você a pensar que a possibilidade de escolher dois doces de morango ou uma mistura é a mesma?

* Agora, você é convidado(a) refletir sobre as seguintes questões:

1. Que combinações saiu mais vezes, dois doces de morango ou uma mistura?

2. Há quantos casos de sabores misturados (morango e baunilha)?

3. Qual é o número de combinações possíveis (tamanho do espaço amostral)?

4. Descreva todos os casos possíveis do espaço amostral e, em seguida, discuta quanto representa cada combinação.

5. Seu palpite inicial estava correto?

( ) Sim. ( ) Não. Por quê?

Fonte: Acervo da pesquisa

A tarefa ${ }^{3}$ foi proposta com a finalidade de perceber como os professores entendem a quantificação de probabilidades por meio da explosão de casos agregados no espaço amostral. Também tencionávamos verificar como os docentes analisariam tais casos para comparar probabilidades.

Destacamos que, em sessões anteriores àquela em que essa tarefa foi proposta, os professores já haviam explorado o conceito de espaço amostral e quantificação de probabilidades. Assim, a sessão foi iniciada com a apresentação da tarefa aos professores, sem quaisquer esclarecimentos prévios por parte dos formadores. Os professores, inicialmente, trabalharam em pequenos grupos; porém, com o calor das discussões, os grupos passaram a interagir entre si.

Na seção seguinte, dedicar-nos-emos à análise e discussão dos resultados. Nela, apresentaremos alguns protocolos com as resoluções dos professores e extratos das discussões registradas em vídeos e áudios.

2 Projeto Observatório da Educação (Obeduc). Auxílio n. ${ }^{\circ}$ 1052/2013. D.O. 30/07/2013: Investigações sobre o Processo de Ensino e de Aprendizagem de Conceitos concernentes à Probabilidade e Estatística. Coordenação feita pelo Professor Doutor Ruy César Pietropaolo.

3 Optamos por adotar o termo "tarefa" da forma como entende Ponte (2005, p.1): Quando se está envolvido numa actividade, realiza-se uma certa tarefa. Uma tarefa é, assim, o objectivo da actividade. 


\section{Análise e Discussão dos Resultados}

O experimento descrito na tarefa consiste em pegar dois doces de um saco que contém três doces: dois de morango (M) e um de baunilha (B). Pede-se para analisar os eventos possíveis, quais sejam: pegar dois doces de morango ou pegar uma mistura (um de morango e um de baunilha). E, em seguida, deve-se inferir qual deles apresenta maior chance de ocorrer. Para deduzir as chances de ocorrência de eventos em um experimento qualquer, faz-se necessário analisar o espaço amostral. Neste caso, é preciso averiguar as possibilidades de resultados $\mathrm{MM}$ ou $\mathrm{MB}$.

As três professoras que afirmaram haver maior chance de Samantha escolher uma mistura não se referiram ao espaço amostral. Diamante ${ }^{4}$, uma delas, analisou a situação com base, predominantemente, na intuição: “Acredito na mistura, pois conseguir os dois doces de morango seria pouco provável; e, na agitação do saco, haverá a mistura (...), haverá três doces, e a escolha é aleatória." Da mesma forma, a professora Alexandrita buscou justificar intuitivamente: "Tirar o mesmo sabor é muita sorte; ao agitar o saco, a possibilidade de mistura é maior, a probabilidade de sair a mistura é maior."

Como ocorreu com as professoras Diamante e Alexandrita, Azurita se apoiou em ideias presentes no conceito de Probabilidade: evento certo e evento provável. Elas haviam sido estudadas em sessões de formação anteriores àquela em que essa tarefa foi proposta. A docente respondeu: "1 morango é $100 \%$, e o outro doce é 50\% para cada." Quando a professora utilizou a expressão "morango é 100\%", acreditamos que ela quis dizer que o doce será de morango em, pelo menos, uma das retiradas. Todavia, a forma como ela se referiu ao sabor baunilha revela, sob nosso ponto de vista, indícios de que Azurita não pensou no espaço amostral: fixou a primeira retirada como um doce de morango e, em seguida, analisou que a chance de obter um doce de morango ou de baunilha, na segunda retirada, seria $50 \%$. Nesse contexto, ela parece ter analisando parcialmente o espaço amostral.

Figura 1 - Interpretação da justificativa da professora

\section{Tarefa Saco de Doces}

\section{Espaço Amostral}

$1^{\text {a }}$ Retirada $2^{\text {a }}$ Retirada

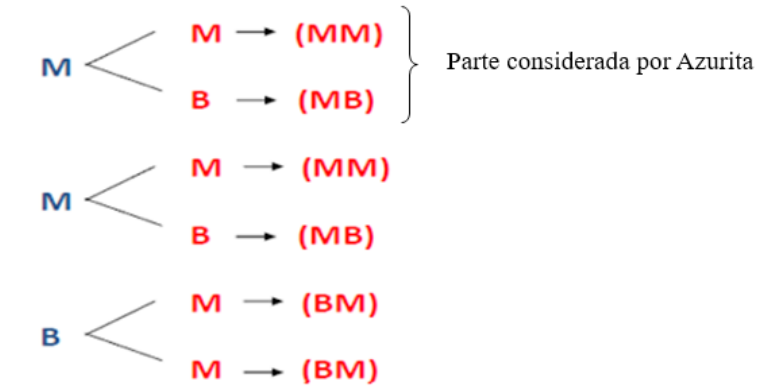

Fonte: Os autores.
Quando a discussão em torno das resoluções se estendeu a todos os participantes, a maioria dos professores afirmou, equivocadamente, que a chance de Samantha escolher dois doces de morango ou uma mistura é a mesma. Porém, nem todos estavam convencidos dessa conclusão. A professora Ametista, por exemplo, quando relatou o raciocínio do grupo de professores com quem ela discutia a tarefa, descreveu a síntese das possibilidades do espaço amostral. É possível que ela não tenha levando em conta que são dois doces de morango. Vejamos a fala da docente:

Pensamos dessa forma: se a Samantha retirar doce de baunilha [referindo-se à primeira retirada], sobrará apenas a possibilidade de sair o doce de morango [mencionando a segunda retirada]; mas, se ela retirar o doce de morango [fazendo alusão à primeira retirada], a possiblidade dela retirar o doce de morango e baunilha é a mesma [indicando a segunda retirada].

Assim como Ametista, Esmeralda descreveu a síntese das possibilidades do espaço amostral; todavia, referiu-se aos termos possibilidades e probabilidade como sinônimos. Tal engano, que parece se configurar em uma compreensão equivocada por parte dos professores, é uma preocupação apontada por alguns estudiosos, como Santos (2015) e Campos et al. (2011). Essa constatação também pode ser vista nesta fala de Esmeralda: "Se ela retirar primeiro o de baunilha, o segundo com certeza será de morango; se retirar primeiro o sabor morango, a probabilidade de o segundo ser de sabor morango é a mesma do de baunilha. O resultado é aleatório."

Painite, outra participante, apresentou argumento semelhante, considerando os dois doces de morango: "Não pensei em nenhuma das suposições com relação à primeira e à segunda [referindo-se a cada retirada]. A minha suposição foi que dependerá do que ela retirará (...), que poderá ser: MM ou MB ou BM.” O argumento da professora Prata, descrito a seguir, evidencia que ela justificou sua resposta, equivocadamente, com base na categoria sabores de doce, e não na quantidade de doces de cada sabor contidos no saco:

Independente de ser 2 doces de morango e 1 de baunilha, a probabilidade é de $50 \%$ para cada doce [referindo-se aos doces de morango e baunilha]. Porque, mesmo havendo mais doces de morango, na hora de escolher será a mesma chance para ambos [ fazendo menção à existência de doces de dois sabores no saco].

Ainda que ela argumentasse com base na probabilidade, estaria equivocada, visto que, neste caso, havia maior probabilidade de Samantha pegar 1 doce de morango na primeira retirada, aproximadamente, $66,7 \%$.

Três professores afirmaram, ainda, que Samantha possui maior chance de escolher dois doces de morango. Argumentaram com base na quantidade de doces de cada sabor, como podemos observar nestas falas:

Professora Jade: Porque o morango há mais quantidade do que baunilha.

4 Usamos nomes de pedras preciosas para preservar a identidade dos participantes do estudo. 
Professora Malaquita: $\mathrm{O}$ fato de ser apenas um doce de baunilha (...) acredito que tem mais chance pelo número de doces e vezes que se pega o doce do saco.

A professora Lápis Lazule chegou à mesma conclusão das professoras Jade e Malaquita. Ela respondeu: "Sim. É a mesma, pois ela poderá pegar um de morango e um de baunilha, como dois de morango. Na verdade, as chances de pegar dois de morango são maiores por haver maior quantidade."

Na resolução de tarefas como essa, há a necessidade de mobilizar os raciocínios combinatório e contrafactual (Nunes et al., 2011). No entanto, os dados extraídos dos protocolos dos professores, não nos ofereceram elementos que indiquem tal mobilização. Em busca de mais evidências sobre a compreensão deles ao resolverem a tarefa, recorremos aos vídeos produzidos naquela sessão de formação.

Encontramos dados interessantes nos extratos das discussões coletivas recortados das gravações em vídeos referentes à segunda parte da tarefa, em que eles foram convidados a descrever o espaço amostral por meio do diagrama de árvores e analisá-lo. Para alguns professores, utilizar o diagrama de árvores para descrever o espaço amostral indicava que os resultados possíveis eram "eventos certos" e que, portanto, o que antes eles haviam analisado como um experimento aleatório deixou de ser, pois, de acordo com sua compreensão, o diagrama de árvores lhes permitia enxergar (manipular) todas as possibilidades:

Professora Malaquita: Aleatoriedade é uma coisa, combinatória é outra.

Pesquisadora: A aleatoriedade não está presente aí? [referindose à situação que estava sendo analisada pelos professores naquele momento].

Professora Malaquita: Eu acho que não. Quando a gente vai fazer a árvore, eu já sei que a gente vai ter que tirar um e combinar com o que sobrou; então, já sei que se trata de um evento que vai ocorrer [fazendo a indicação de "eventos certos”]. (Diálogo, Sessão de formação, 2016).

Reconhecer tratar-se de um experimento aleatório não foi o único desafio manifestado pelos professores. Os argumentos por eles apresentados em relação àquele espaço amostral (Figura 2) revelaram que, embora tenham mobilizado o raciocínio combinatório, eles apresentaram dificuldades em relação à descrição e à análise dos resultados possíveis.

Figura 2 - Resolução da professora Malaquita para a tarefa Saco de Doces

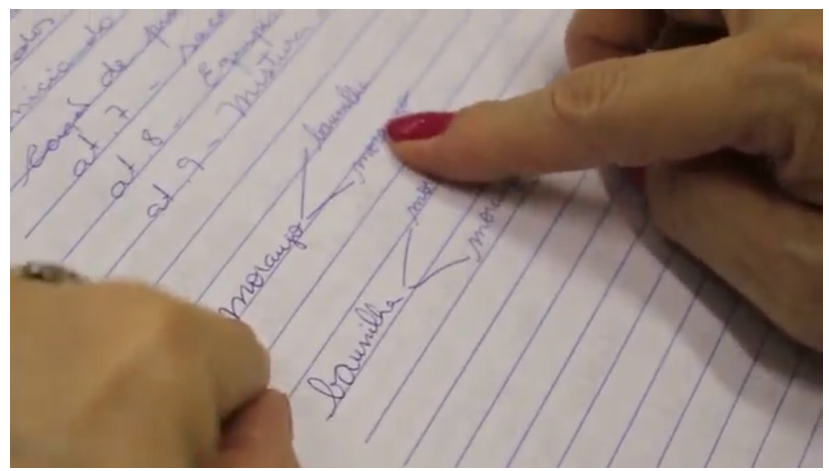

Fonte: Acervo da pesquisa
Pesquisadora: Então, você está descrevendo as possibilidades, certo?

Professora Malaquita: Sim. Qual saiu mais vezes?

Pesquisadora: Qual?

Professora Malaquita: A que saiu mais vezes é a mistura, mas aqui a possibilidade é igual, porque tanto faz tirar um como o outro: se eu tirar baunilha vai sobrar morango; se eu tirar morango, pode vir ou baunilha ou morango.

Pesquisadora: E quantas possibilidades vocês encontraram? Quantas combinações?

Professora Malaquita: Quatro. Olha: morango, baunilha; morango, morango; baunilha, morango; baunilha, morango [a professora relacionou todas as combinações enquanto apontava para a árvore que ela construiu].

Pesquisadora: E o outro doce de morango? Não são dois doces de morango?

Professora Malaquita: Então! Mas, se eu tirar um morango [referindo-se à primeira retirada], eu vou ficar com um baunilha ou um morango [apontou para a segunda retirada]. (Diálogo, Sessão de formação, 2016).

Durante a análise, a maior dificuldade da professora Malaquita estava em perceber que seriam realizadas duas retiradas: para a primeira retirada, havia três possibilidades (dois doces de morango e um de baunilha); e para a segunda retirada, havia duas (dois doces de morango ou um de morango e um de baunilha). Essa conversa ocorria no âmbito de um dos grupos que havia sido formado inicialmente. Porém, diante das discussões, outros professores, após a pesquisadora convidar o grupo a pensar, envolveram-se na análise:

Pesquisadora: Vamos pensar.

Professora Esmeralda: Vai repetir? Porque são dois morangos. Pesquisadora: São três doces.

Professor Citrino: É. São dois de morango e um de baunilha. Professora Ametista: Eu penso assim: se eu for pensar na primeira retirada, há maior possibilidade de tirar um de morango, porque são dois de morango e um de baunilha; mas, quando eu tirar o de morango, a possibilidade [referindo-se à segunda retirada] fica igual de tirar tanto o de morango como o de baunilha, porque eu vou ter só um de morango e um de baunilha dentro do saco.

Pesquisadora: Então, você concorda que, na primeira retirada, você pode tirar um de morango, ou um de baunilha ou um de morango?

Professora Ametista: Sim. Morango ou baunilha, ou uma terceira que pode ser morango. (Diálogo, Sessão de formação, 2016).

A estratégia de utilizar-se do diagrama de árvores para descrever o espaço amostral mostrava-se um recurso favorável para a análise e a compreensão de alguns professores. Porém, a professora Malaquita ainda levou algum tempo para convencer-se tanto das possibilidades daquele experimento quanto da ideia de que se tratava de um experimento cujos resultados são de natureza aleatória.

Professora Malaquita: Mas a gente não está falando de morango um; e morango dois... Você está falando de quantas possibilidades. Eu estou falando de uma retirada. O que eu entendi era que eu teria que ter a primeira retirada e a segunda retirada, e não uma terceira.

Pesquisadora: Sim. São duas retiradas. Mas, para a primeira retirada, eu teria três possibilidades, não?

Professora Ametista: Mesmo considerando essa terceira, a quantidade de morango, baunilha ainda é maior.

Professora Malaquita: A possibilidade da mistura ainda é 
maior.

Professora Ametista: Daí aumenta para quatro possibilidades de combinação "baunilha e morango".

Professora Malaquita: Mas é muito aleatório.

Pesquisadora: Você admitiu agora que é aleatório.

Professora Malaquita: Isso [respondendo afirmativamente para o fato de o evento ser aleatório]. Mas nós fizemos a árvore; e, para mim, a árvore era combinatória.

Pesquisadora: Sim. Para fazer a árvore, você usa o raciocínio combinatório, que está intimamente associado à probabilidade.

Professora Malaquita: Então, era por isso que você estava tentando que eu ligasse aleatoriedade com o raciocínio combinatório e também a probabilidade. Eles não são a mesma coisa, mas estão ligados. (Diálogo, Sessão de formação, 2016).

O raciocínio probabilístico pode gerar dificuldades, visto que apresenta características, muitas vezes, contrárias a nossa intuição (Nunes et al., 2011). A dificuldade, por exemplo, com a compreensão da ideia de aleatoriedade pôde ser percebida nos extratos descritos. Porém, podemos afirmar que as noções envolvidas no conceito de Probabilidade estavam sendo construídas e compreendidas pelos professores ao longo da formação, de modo que eles adquiriam raciocínios mais elaborados e, naturalmente, maior envolvimento com as tarefas.

Ao final da discussão, os professores, de maneira geral, com base na ideia parte-todo, concluíram haver $\frac{2}{6}$ de chance de Samantha retirar a combinação morango-mơrango e $\frac{4}{4}$ de chance de retirar a mistura (morango e baunilha), item 4 . Porém, parte da análise feita por alguns docentes nos chamou a atenção, pois consideraram que a chance de Samantha conseguir 2 doces de morango era de " $50 \%$ ", ao passo que a de conseguir uma mistura era de " $100 \%$ ". Eles não consideraram a razão que representava as duas possibilidades de retirada, focaram seu olhar somente em seus numeradores e justificaram que a mistura tem o dobro de possibilidade em comparação com a combinação morango-morango.

Após analisarmos, coletivamente, essa forma de raciocinar, procuramos esclarecer alguns aspectos. Por exemplo, discutimos com eles a necessidade de, na análise de probabilidades, de acontecimentos como o apresentado na tarefa, estabelecer relações, proporções, da parte com o todo. A partir disso, é possível realizar comparações que favorecerão conclusões sobre as probabilidades de ocorrência de um ou de outro evento.

Também indicamos para eles que a probabilidade, nesse caso, correspondia, efetivamente, a uma proporção entre um resultado específico e um conjunto de resultados possíveis. Assumimos que a Probabilidade envolve características que devem ser observadas, por exemplo: na comparação de probabilidades, deve-se considerar o tamanho da amostra, pois há casos em que a probabilidade pode ser a mesma em amostras de diferentes tamanhos.

Em decorrência disso, eles, coletivamente, analisaram de novo a situação e tiraram suas conclusões sobre as chances de ocorrência de cada evento daquele espaço amostral e as respectivas probabilidades, conforme registrou a professora Jade, cujas probabilidades foram representadas na forma de razão e percentagem.

Figura 3 - Resolução apresentada por Jade, que conduziu a discussão coletiva entre os professores na tarefa Saco de doces

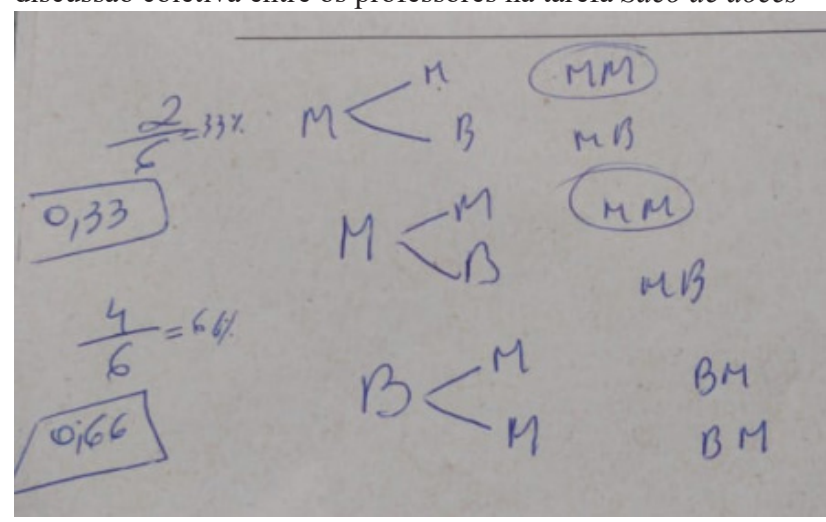

Fonte: Acervo da pesquisa

Diante disso, ratificamos que a compreensão do espaço amostral envolve um tipo de raciocínio e que a forma de o analisar requer a mobilização de outras noções envolvidas no conceito. Citamos como exemplo o entendimento da aleatoriedade e o raciocínio combinatório (Bryant \& Nunes, 2012).

No que se refere ao Conhecimento Comum do Conteúdo (Ball et al., 2008), foco de nossa atenção durante nossa análise, constatamos que os professores ainda possuíam fragilidades. Porém, consideramos que essas fragilidades foram, em alguma medida, superadas.

Além disso, constatamos, combasenas discussões ocorridas nas sessões que se sucederam a que foi aqui analisada, que os professores ampliaram tal conhecimento, pois mostraram-se capazes de: avaliar a chance de ocorrência de determinados eventos; e descrever e analisar espaços amostrais de diferentes experimentos, utilizando-se da árvore de possibilidades. Parte dessas compreensões foram observadas durante a exploração da tarefa Mistura de bolos, que propõe analisar combinações de bolos que seriam produzidos para uma festa de fim de ano de algumas escolas, sendo que a fábrica de bolos contratada produzia três sabores diferentes de bolo (laranja, limão e morango), recheio (baunilha, creme e geleia) e cobertura (nozes, chocolate e cereja). A análise consistia em fazer caixas para cada combinação distinta de bolo. Além disso, após essa primeira análise, outras deveriam ser realizadas, ampliando as discussões.

Entretanto, como a referida tarefa não é foco de discussão neste texto, importa afirmar que o espaço amostral do experimento realizado nessa tarefa envolve um número maior de possibilidades. Mesmo assim, os professores não apresentaram dificuldade em descrevê-lo e, consequentemente, analisaram-no com tranquilidade, conforme registros recortados de vídeos (Figuras 4 e 5). 
Figura 4 - Resolução de professores para a tarefa Mistura de Bolos

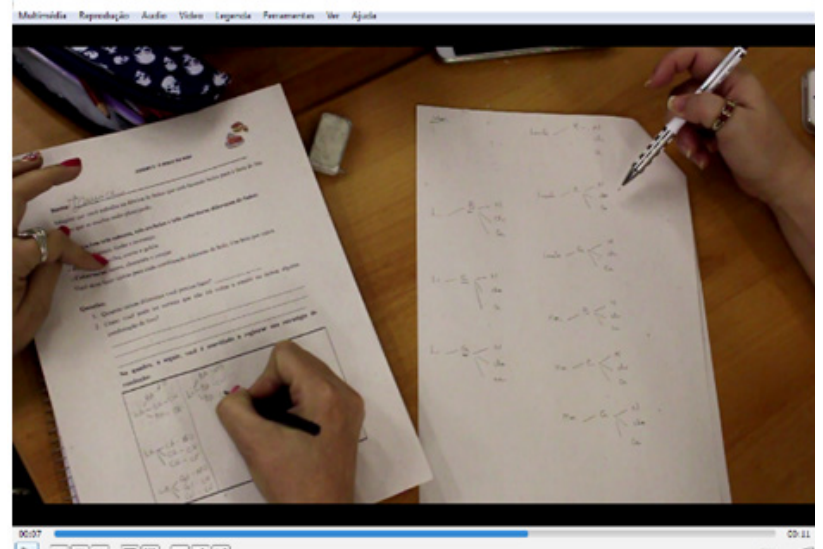

Dim

Fonte: Acervo da pesquisa

Figura 5 - Resolução de professores para a tarefa Mistura de Bolos

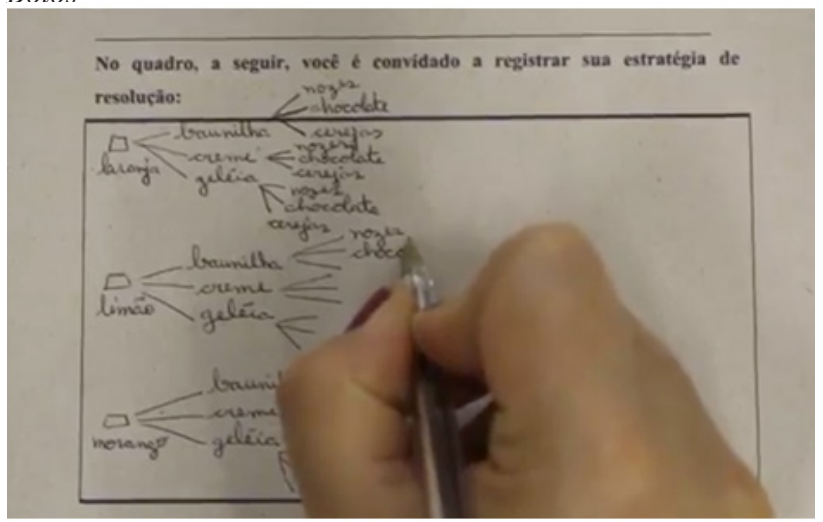

Fonte: Acervo da pesquisa

Tal fato é relevante uma vez que, no início do processo formativo, os professores, de certa maneira, apoiavam-se, sobretudo, em listas que, muitas vezes, levava-os a análises equivocadas. Após as discussões sobre as resoluções da tarefa aqui apresentada, os docentes passaram a adotar a árvore de possibilidades como principal estratégia de descrição e análise de espaços amostrais. Fischbein, Pampu \& Minzat (1970) já discutiam que o uso de tal recurso favorece o desenvolvimento do raciocínio combinatório, visto que, em situações em que é explorado esse raciocínio, a árvore de possibilidades ajuda a enumerar e sistematizar combinações.

Além disso, enfatizamos, com base em Nunes et al. (2011), o papel que desempenha o espaço amostral para a compreensão e cálculo de probabilidades, “(...) já que a solução é bastante óbvia para alguém que conheça todas as possibilidades.” (Bryant \& Nunes; 2012, p. 5). Os resultados aqui descritos revelam que as discussões oriundas da exploração das tarefas propostas durante a formação em que este estudo foi desenvolvido favoreceram o início de um processo de desenvolvimento do Conhecimento Especializado de Conteúdo (Ball et al., 2008) por parte dos professores.

Ressaltamos que, na análise desses resultados, optamos por apresentar extratos da sessão de formação em que estão evidenciadas as discussões e as reflexões individuais e coletivas dos professores a respeito das ideias probabilísticas exploradas na tarefa. Assim, do ponto de vista da formação, consideramos que o referido processo formativo contribuiu para o desenvolvimento profissional dos participantes, uma vez que favoreceram a discussão, a reflexão, a construção e a ampliação da compreensão de ideias e conceitos associados à temática estudada. Destacamos, porém, que não temos a pretensão de afirmar que tais compreensões foram plenamente desenvolvidas durante a referida formação.

\section{Conclusão}

Como explicitado na seção introdutória deste texto, procuramos analisar a compreensão dos professores, participantes desta investigação sobre espaço amostral e quantificação de probabilidades. Mais especificamente, buscamos identificar aspectos que apontassem para o Conhecimento Comum de Conteúdo (Ball et al., 2008) manifestado na resolução de uma tarefa proposta em uma das sessões de formação, cenário em que o estudo foi desenvolvido.

Em termos de resultados, consideramos que alguns professores investigados, inicialmente, apresentaram dificuldades em perceber tratar-se de um experimento em que os resultados são aleatórios e em discriminar o respectivo espaço amostral. No entanto, elas foram superadas à medida que as discussões coletivas ocorreram. Além de descrever as possibilidades daquele espaço amostral, eles desenvolveram compreensões em relação à quantificação de probabilidades. Ressaltamos, porém, que tais compreensões não ocorreram de maneira imediata.

Nesse sentido, não só consideramos que o Conhecimento Comum de Conteúdo foi desenvolvido e/ou ampliado pelos professores, mas também verificamos que ocorreu o início de um desenvolvimento do Conhecimento Especializado de Conteúdo relativo, por exemplo, às diferentes formas de descrever espaços amostrais e de representar as respectivas probabilidades. Isso permitirá aos participantes, no ensino dessa temática, explorar tarefas como a que foi proposta a eles, antecipar erros dos estudantes, identificar possíveis causas para os equívocos dos alunos, justificá-las do ponto de vista da Matemática e, consequentemente, buscar estratégias de intervenção que favoreçam a compreensão e a aprendizagem dos discentes.

Por último, ressaltamos a importância dos cursos de formação continuada como contributo ao professor para o desenvolvimento de conhecimentos para o ensino de Matemática. Tais formações devem objetivar desenvolvimento profissional do professor, especialmente, no que se refere aos Conhecimentos Especializados de Conteúdo e à capacidade de refletir sobre tais conhecimentos.

\section{Agradecimentos:}

O presente trabalho foi realizado com apoio da Coordenação de Aperfeiçoamento de Pessoal de Nível Superior (Capes), 
Código de Financiamento 001.

\section{Referências}

Ball, D. L., Thames, M. H., \& Phelps, G. (2008). Content knowledge for teaching: what makes it special? Journal of Teacher Education, Pennsylvania, 59(5), 389-407.

Batanero, C. (2016). Posibilidades y retos de la enseñanza de la probabilidad en la educación primaria. In Semur (Ed.), Actas del $6^{\circ}$ Congreso Uruguayo de Educación Matemática, Montevideo. Recuperado em http://semur.edu.uy/curem6/ actas/pdf/48.pdf

Batanero, C., \& Godino, J. D. (2002). Estocástica y su didáctica para maestros. Granada: Departamento de Didáctica de las Matemáticas. Universidad de Granada. Recuperado em http:// www.ugr.es/ jgodino/edumat-maestros/

Batanero, C., Godino, J. D., \& Roa, R. (2004). Training teachers to teach probability. Journal of Statistics Education, 12(1). Recuperado em https://tandfonline.com/loi/ujse20

Batanero, C., Gómez, E., Contreras, J. M., \& Diaz, C. (2015). Conocimiento Matemático de Profesores de Primaria en Formación para la Enseñanza de la Probabilidad: un estudio exploratorio. Práxis Educativa, 10(1), 11-34. Recuperado em http://www.ugr.es/ batanero/pages/formacionprofesores. html

Batista, R., \& Borba, R. E. S. R. (2016). No jogo é a moeda que diz, não é a gente que quer não: o que dizem as crianças sobre a probabilidade. VIDYA, 36(2), 237-255.

Bogdan, R., \& Biklen, S. (1999). Investigação qualitativa em educação. Uma introdução à teoria e aos métodos. Porto: Porto.

Bryant, P., \& Nunes, T. (2012). Children's Understanding of Probability: a literature review. London: Nuffield Foundation. Recuperado em http://www.nuffieldfoundation. org/sites/default/files/files/Nuffield_CuP_FULL_REPORTv_ FINAL.pdf

Campos, T. M. M., \& Carvalho, J. I. (2016). Probabilidade nos Anos Iniciais da Educação Básica: contribuições de um programa de ensino. EM TEIA - Revista de Educação Matemática e Tecnológica Iberoamericana, 7(1), 1-18.

Campos, T. M. M., Kataoka, V. Y., Nogueira, R. L. de, Nunes, T., Bryant, P., Tonouti, R. R., \& Santos, J. (2011). Estudo sobre Probabilidade e Risco no Ensino Fundamental I. Programa de Pós-Graduação em Educação Matemática, Universidade Anhanguera de São Paulo.

Campos, T. M. M., \& Pietropaolo, R. C. (2013). Um estudo sobre os conhecimentos necessários ao professor para ensinar noções concernentes à probabilidade nos Anos Iniciais. In R. Borba \& C. Monteiro (Org.), Processos de ensino e aprendizagem em Educação Matemática (pp. 55-91). Recife: UFPE.

Cardeñoso, J. M., \& Azcárate, P. (1995). Tratamiento del conocimiento probabilístico en los proyectos y materiales curriculares. Revista sobre La Enseñanza y Aprendizaje de Las Matematicas - SUMA, 20, 41-51.

Cazorla, I. M. (2009). O ensino de Estatística no Brasil. Sociedade Brasileira de Educação Matemática. Recuperado em http:// www.sbem.com.br/gt_12/arquivos/cazorla.htm.

Coutinho, C. Q. e S. (2001). Introduction aux Situations Aléatoires dès le Collège: de la modélisation à la simulation d'expériences de Bernoulli dans l'environnement informatique Cabri-géomètre II (Tese de Doutorado, Univ.
J. Fourier). Recuperado em http://www.pucsp.br/ cileda/ theseCileda.PDF.

Dias, A. L. B. (2004). Projeto Gestar: ensino de probabilidade. Brasília MEC.

Fernandes, J. A., Serrano, M. M. G., \& Correia, P. F. (2016). Definição de acontecimentos certos na extração de berlindes de um saco. Revista de Ensino de Ciências e Matemática. Acta Scientiae, 18(1), 83-100. Recuperado em http://www. periodicos.ulbra.br/index.php/acta/article/view/1619/1500.

Fischbein, E., Pampu, I., \& Minzat, I. (1970). Effects of age and instruction on combinatory ability in children. The British Journal of Educational Psichology, 40.

Gal, I. (2005). Towards "probability literacy" for all citizens: Building blocks and instructional dilemmas. In: JONES, G. A. (Ed.). Exploring probability in school: Challenges for teaching and learning. Netherlands: Kluwer Academic Publishers, p.39-63.

Kataoka, V., Rodrigues, A., \& Oliveira, M. (2007). Utilização do conceito de Probabilidade Geométrica como recurso didático no ensino de Estatística. In SBEM (Org.). Anais do IX Encontro Nacional de Educação Matemática, Belo Horizonte.

Lopes, C. E. (2012). A educação estocástica na infância. Revista Eletrônica de Educação, 6(1), 160-174.

Lopes, C. E. (2003). O Conhecimento Profissional dos professores e suas relações com Estatística e Probabilidade na Educação Infantil. $290 \mathrm{f}$. (Tese de Doutorado, Universidade Estadual de Campinas), Campinas, Brasil.

Brasil. Ministério da Educação. (2017). Base Nacional Curricular Comum (BNCC). Brasília: MEC.

Portugal. Ministério da Educação. (2007). Programa de Matemática do Ensino Básico. Lisboa.

Nacarato, A. M., \& Grando, R. C. (2013). Estatística e probabilidade na educação básica: professores narrando suas experiências. Campinas: Mercado de Letras.

NCTM. (2000). Principles and standards for school mathematics. Reston, Virginia. Recuperado em http://standards.nctm.org

Nunes, T., \& Bryant, P. (2011). Understanding risk and uncertainty: the importance of correlations. EM TEIA - Revista de Educação Matemática e Tecnológica Iberoamericana, 2(2), $1-23$.

Nunes, T., Bryant, P., Evans, D., \& Barros, R. (2011). Children's Understanding of Probability and Risk. Oxford: Department of Education, University of Oxford.

Ponte, J. P. (2012). Estudiando el conocimiento y el desarrollo profesional del profesorado de matemáticas. In N. Planas (Ed.), Teoría, crítica y prática de la educación matemática (pp. 83-98). Barcelona: Graó.

Ponte, J. P. (2005). Gestão curricular em Matemática. In GTI (Ed.), O professor e o desenvolvimento curricular (pp. 1134). Lisboa: APM.

Real Decreto 1513 (2006, 7 de diciembre). Se establecen las enseñanzas mínimas de la educación primaria. Madrid. Recuperado em www.mec.es/files/rdprimaria-y-anexos.pdf.

Santos, J. A. F. L. (2015). A produção de significações sobre combinatória e probabilidade numa sala de aula do $6^{\circ}$ ano do ensino fundamental a partir de uma prática problematizadora. (Tese de Doutorado em Educação). Universidade São Francisco, Itatiba. 
Silva, M. A. (2011). A Presença da Estatística e da Probabilidade no Currículo Prescrito de Cursos de Licenciatura em Matemática: uma análise do possível descompasso entre as orientações curriculares para a Educação Básica e a formação inicial do professor de Matemática. Bolema, 24(40), 747-764.

Shulman, L. (1986). Those Who Understand: Knowledge Growth in Teaching. Educational Researcher, 15(2), 1-24. 